\title{
Social Intelligence Counseling Intervention to Reduce Bullying Behaviors Among Thai Lower Secondary School Students: A Mixed-method Study
}

\author{
Samith Jueajinda', Orapin Stiramon ${ }^{2}$, Chatchai Ekpanyaskul ${ }^{3}$ \\ ${ }^{1}$ Behavioral Science Research Institute, Srinakharinwirot University, Bangkok, Thailand; ${ }^{2}$ Department of Psychology, Faculty of Social Sciences, \\ Kasetsart University, Bangkok, Thailand; ${ }^{3}$ Department of Preventive and Social Medicine, Faculty of Medicine, Srinakharinwirot University, Bangkok, \\ Thailand
}

Objectives: To develop and investigate the effectiveness of an integrative counseling intervention for enhancing social intelligence and reducing bullying behaviors among lower secondary school students in Bangkok, Thailand.

Methods: An interventional mixed-method design was employed in 2 phases. Phase 1 involved the development of a qualitative method-based integrative counseling program from key informants using the eclecticism technique. In phase 2, a randomized controlled trial with a wait-list control was conducted and qualitative research was performed with students who demonstrated bullying behaviors. Demographic data, Social Intelligence Scale (SIS) scores, and Bullying-Behavior Scale (BBS) scores were collected at baseline. Changes in SIS scores and qualitative findings obtained from in-depth interviews were examined after counseling ended, and BBS scores were collected again 1 month later.

Results: The developed social intelligence counseling program included eight 1-hour weekly sessions consisting of 3 components: (1) social awareness, (2) social information processing, and (3) social skills. After receiving this intervention, scores for the SIS overall $(p<0.001)$ and all of its components $(p<0.05)$ were significantly enhanced in the experimental group compared to the control group. Moreover, the mean BBS scores in the experimental group significantly decreased 1 month after counseling $(p=0.001)$. With regard to the qualitative research results, the experimental students demonstrated improvements in all components of social intelligence.

Conclusions: The results indicated that a preventive counseling program may enhance social intelligence, decrease bullying behaviors among lower secondary school students, and prevent further incidents of school violence. However, further studies in various population subgroups should also be performed.

Key words: Preventive program, Counseling, Social intelligence, Violence, Bullying

Received: March 2, 2021 Accepted: July 15, 2021

Corresponding author: Chatchai Ekpanyaskul Department of Preventive and Social Medicine, Faculty of Medicine, Srinakharinwirot University, 114 Sukhumvit 23, Wattana, Bangkok, Thailand

E-mail: dr_chatchai@hotmail.com

This is an Open Access article distributed under the terms of the Creative Commons Attribution Non-Commercial License (https://creativecommons.org/licenses/bync/4.0/) which permits unrestricted non-commercial use, distribution, and reproduction in any medium, provided the original work is properly cited.

\section{INTRODUCTION}

Bullying of students in schools has clearly increased considerably, and violence in schools has become a widespread problem across the world. According to a study by the United Nations Educational, Scientific and Cultural Organization, nearly one-third of students in the world have experienced bullying [1]. In addition, the World Health Organization surveyed teen- 
age mental health in Southeast Asian countries and found that $30 \%$ of Thai students had been bullied in school [2]. Data collected by the Department of Mental Health and the Ministry of Public Health showed that the proportion of students who have been bullied in Thailand is the second-highest in the world and is likely to steadily increase. Furthermore, bullying behaviors among students are considered an important problem that needs to be addressed through improvement toward appropriate behavior. If this issue is neglected, students with bullying behaviors may grow into adults who are addicted to alcohol or illegal drugs, demonstrate stealing behaviors, cannot finish school, have premature sexual or violent behaviors, or become criminals [3]. Moreover, the problem of bullying also affects students who are bullied in many ways; for instance, bullying causes them to feel shame and negative attitudes toward school, earn bad grades, run away from home, drop out from school before graduating, and experience lower self-esteem or a lack of confidence $[4,5]$. Bullying behaviors, which are considered a type of inappropriate and aggressive behaviors, include intimidation, harassment, mocking, and physical and emotional abuse. In addition, these types of behaviors may continue for a long time and may have even more severe effects in the future $[6,7]$.

Bullying prevention is becoming recognized as a public health issue and a challenge for community mental healthcare. Prevention can be conducted in multiple settings and in an ecological context. Recommended strategies to decrease bullying problems were derived from studies of universal preventive programs, such as social-emotional education for youth, and selective preventive programs, such as social and emotional learning skills training for students who are at risk for bullying. In contrast, research on models for indicated prevention, such as intensive support and activities for those who already display bullying behavior or have a history of being bullied, is limited. Likewise, the effectiveness of programs in reducing or preventing these problems has rarely been tested, particularly through randomized controlled trials [8]. Therefore, interventional studies in students experiencing bullying behavior are critical for the development of proper solutions.

Counseling is an evidence-supported preventive program that is more sustainable and may specifically empower students who experience bullying behaviors to accomplish their goals and achieve mental well-being by introducing necessary changes in their ways of thinking, feeling, and behaving. Counseling is a goal-based collaborative process involving a non-judgmental, supportive counselor who works with a client to tell stories, set viable goals, and develop strategies and necessary plans to decrease bullying behavior. Despite integrative counseling programs and their effectiveness, studies in the field of community mental health at school are limited [9].

In terms of program content, social intelligence is a current interest in school psychology, but only a few studies have explored social intelligence in the context of bullying and violence. Regarding the capacity to know oneself and others, Sameer [10] and Shekarey et al. [11] found that social intelligence and aggressive behaviors are significantly related, with students with high social intelligence showing fewer aggressive behaviors and students with low social intelligence showing more aggressive behaviors. Goleman [12] and Albrecht [13] found that people with high social intelligence consistently have the ability to create good feelings for others, are considerate of the feelings of themselves and others, and can adapt well in society. Therefore, the idea of building social intelligence through a counseling program is more sustainable than training, and counseling can serve as a strategy to reduce the emotional and behavioral problems of bullied students.

Based on the rationale discussed above, the objectives of this study were as follows: (1) to develop a bullying prevention program and an individual social intelligence counseling program that fit the indicated population of students exhibiting bullying behaviors and (2) to formulate a study hypothesis to investigate the effectiveness of this intervention for strengthening the social intelligence of students who demonstrate bullying behaviors and reducing bullying behaviors among students, which may in turn prevent future incidents of school violence.

\section{METHODS}

\section{Study Design}

This study employed mixed-method research with an embedded design [14]. A diagram of the overall study flow is shown in Figure 1.

\section{Participants}

This study was conducted in 2 phases. Phase 1 involved qualitative research through interviews with 18 key informants who were selected by purposive sampling to obtain components and guidelines for enhancing the social intelligence of students displaying bullying behaviors. The key informants were selected to include Thai secondary school students aged 12-18 years 
Phase 1: Counseling program development (qualitative research)

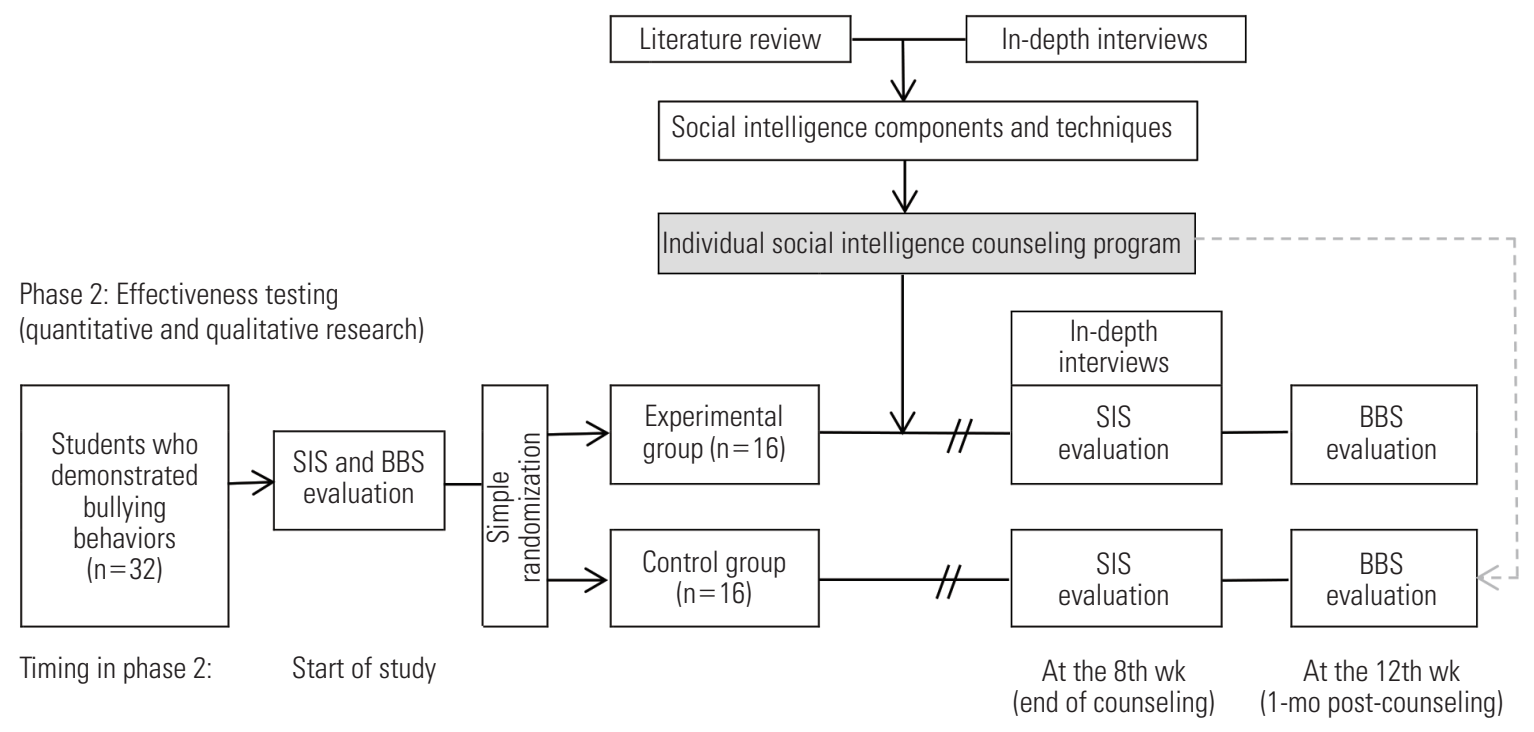

Figure 1. Diagram of the overall research process in this study. SIS, Social Intelligence Scale; BBS, Bullying-Behavior Scale.

who had experiences of bullying behavior $(n=5)$, the parents of those students, who were aged $35-50$ years $(n=5)$, teachers with more than 2 years of teaching experience in secondary school $(n=5)$, and experts with experience in child and adolescent psychology $(n=3)$, including social worker, clinical psychologist, and psychology instructor. This number was sufficient for data saturation [15]. Phase 2 involved experimental research conducted in 3 government-operated lower secondary schools in Bangkok, Thailand with high bullying statistics recorded in the student support system. The sample size for this study was determined using the $G$ *Power program with the $F$-test with the following parameter values: effect size $(\mathrm{f})=$ $0.6, \alpha=0.05$, power $=0.9$, degree of freedom $=1$, and number of covariates $=1$ [16]. The resulting computation concerning the scope of the samples revealed that the minimum overall sample size was 32 individuals. The participants were selected using purposive sampling among Thai lower secondary school students with repeated bullying behaviors as recorded in student support systems or suitable students recommended by teachers. The inclusion criteria were as follows: (1) students who were available and able to participate voluntarily throughout the duration of the experiment, and (2) students who were granted permission from their parents to participate in this study. The exclusion criteria were students with concentration problems that hindered participation in this study and students with communication problems.

\section{Procedure}

Development of the social intelligence counseling program

To formulate the interview questions, phase 1 involved qualitative research beginning with a review of documents and studies related to enhancing social intelligence. The interviews were conducted with 18 key informants. The data were summarized and analyzed through content analysis to be used in the development of the components for a social intelligence counseling program. This program was developed in accordance with the concepts of Corey [9] on technical-eclectic individual counseling, which selects and integrates counseling techniques from various psychological theories by considering their suitability and conformity with social intelligence components. These counseling theories included the following: (1) person-centered counseling theory, (2) Gestalt counseling theory, and (3) behavioral counseling theory. An expected outcome was set for each session to determine whether each social intelligence component was fulfilled. The content validity of this integrative counseling program was based on assessments by 5 experts in child and adolescent psychiatry, counseling, and guidance, who assigned index of item-objective congruence (IOC) scores ranging from 0.8 to 1.0 .

\section{Effectiveness of the social intelligence counseling intervention}

The effectiveness of this program was studied by quantitative research using a randomized controlled trial with a wait-list con- 
trol design and qualitative analyses. All of the study participants were given a self-administered questionnaire to evaluate baseline data. The questionnaire included demographic data questions, the Tromso Social Intelligence Scale (SIS), and the Olweus Bully/Victim Questionnaire. The participants then underwent simple randomization into both groups. The experimental group underwent an individual social intelligence counseling program for a total of 8 weeks, while the control group had to wait until the experiment was completed before participating in the intervention upon completion of the study. All of the counseling activities were run by a doctoral student in applied psychology with more than 300 hours of counseling experience.

Upon completion of the integrative counseling program by the experimental group, the researchers used the social intelligence questionnaire again to collect data from both groups to evaluate changes in social intelligence. This phase of the study also included an interpolation of qualitative research methods by conducting interviews with students in the experimental group after finishing the program. The information gathered in the interviews provided deeper insights into the results regarding the effectiveness of the social intelligence counseling program for individuals. The interviews aimed to identify changes in students' social intelligence throughout the course of the counseling program. One month after the counseling program ended, both groups were re-evaluated for changes in their bullying behaviors.

\section{Measures/Instruments}

\section{Semi-structured interviews in phases 1 and 2}

The semi-structured interviews in phase 1 involved interview forms created by studying related documents and research. The information obtained was analyzed and summarized into guidelines for creating questions for the social intelligence counseling program. The interview questions were open-ended, allowing the key informants to have more freedom when answering the questions. The answers from the interviews were collected and analyzed further for program development. For the semistructured interviews in phase 2 , the interview questions were created from the components of social intelligence. These interviews were conducted only with the participants in the experimental group to confirm social intelligence improvements.

\section{Social intelligence scale}

For social intelligence assessment, this study utilized scores from the Tromso SIS questionnaire [17] translated into the Thai language by the forward and backward translation method. The scale is a rating tool based on the Likert scale, and five levels are used to rate items (1, strongly disagree; 2 , disagree; 3 , neither agree nor disagree; 4 , agree; 5 , strongly agree), with a total of 21 questions. The maximum SIS score is 105 points, while the minimum SIS score is 21 points. The scale contains 3 components, with 7 items in each, measuring social intelligence, including social awareness, social information processing, and social skills. The content validity of this questionnaire was assessed by 5 experts in counseling and psychology and was assigned an IOC of 1.0. This questionnaire was also tested for reliability on 50 secondary school students, among whom the Cronbach alpha coefficient of reliability was 0.95 .

\section{Bullying behavior questionnaire}

To evaluate bullying behaviors, this study utilized scores from the Olweus Bully/Victim Questionnaire, which was developed by Olweus [18] and then translated into Thai and utilized in psychology research by Tapanya [19]. This questionnaire consists of 39 self-report questions, including questions about being bullied or bullying other students. However, this study chose to use only 10 questions about bullying others, because these questions served as sufficient indicators of bullying problems [20]. The questionnaire had a maximum Bullying-Behavior Scale (BBS) score of 50 points and a minimum BBS score of 10 points. The frequency of bullying can be divided into 5 levels: level 1, no bullying in the past 2-3 months; level 2, bullying 1-2 times in the past 2-3 months; level 3, bullying 2-3 times per month; level 4 , bullying once a week; and level 5 , bullying 3-4 times a week. This questionnaire was tested for reliability simultaneously on the same group of students used to test the reliability of the SIS, and the Cronbach alpha coefficient of reliability was 0.95 .

\section{Statistical Analysis}

The qualitative data were analyzed through content analysis in phase 1 and at the end of counseling in phase 2. Qualitative data were analyzed using the Fisher's exact tests, while quantitative data were assessed for normality using the ShapiroWilk test. The data were found to follow a normal distribution; therefore, parametric statistics, including the independent $t$ test, were used to compare groups, and the dependent $t$-test was used to compare the same groups before and after certain periods. To analyze the effectiveness of this study intervention and post-counseling bullying behaviors (defined as the depen- 
dent variable) between the experimental group who received the counseling program (defined as the independent variable) and the control group, the original choice for statistical testing was analysis of covariance (ANCOVA) using changes in SIS scores as a covariate. The assumptions of ANCOVA were assessed as follows: (1) homogeneity of variance; (2) the covariate was linearly related to the dependent variable; and (3) homogeneity of regression slopes. Unfortunately, the data did not meet the above criteria in terms of the covariate, which was not linearly related to the dependent variable. Eventually, analysis of variance (ANOVA) was used instead of ANCOVA to assess changes in bullying behavior, which represented one of the main objectives of this study. The significance level of this study was set at a $p$-value $<0.05$ [21].

\section{Ethics Statement}

The study was approved by the Human Research Ethics Committee of Srinakharinwirot University (SWUEC/E-225/2561). Before data collection in each phase, the researchers asked for cooperation from the sample group by introducing and clarifying the objectives of this study. The study was conducted only after the participants and their parents consented to participate. The participants were able to discontinue participation in the study at any time before the study was completed without consequences. All of the answers and information collected in this study were kept confidential.

\section{RESULTS}

\section{Phase 1}

An analysis of the in-depth interview data revealed that enhancement of the social intelligence of students who demonstrated bullying behaviors consisted of 3 principal components: (1) social awareness, which consists of emotional self-awareness, awareness of the emotions of others, and situational awareness in society; (2) social information processing, which consists of an understanding of human behavior and social situations; and (3) social skills, which consist of appropriate emotional expressions and behaviors. These components are shown in Table 1. The analysis of the interview data revealed that social intelligence consists of 2 components: (1) social awareness, which includes primal empathy, harmonization, empathic accuracy, and social cognition (social information processing); and (2) how this awareness or social facility is implemented in daily life, which consists of synchrony, self-presentation, influence, and concern. Moreover, the in-depth interview results indicated 5 elements of social intelligence, including situational awareness, presence, authenticity, clarity, and empathy.

The 3 components of social intelligence were used to create and develop the social intelligence counseling program, which involved individual counseling within the technical-eclecticism framework to enhance social intelligence. This integrative counseling program consisted of 3 steps: initiation, process, and

Table 1. The social intelligence components as extracted from the content analysis in phase 1 qualitative study

\begin{tabular}{|c|c|}
\hline Components $^{1}$ & Example of quotations \\
\hline \multicolumn{2}{|l|}{ Social awareness } \\
\hline $\begin{array}{l}\text { Awareness of one's own emotions } \\
\text { and those of others (12) }\end{array}$ & $\begin{array}{l}\text { "If he is aware of himself, he will be aware of other people's feelings; But if he doesn't understand even himself or } \\
\text { what he wants, he will behave in the wrong way" }\end{array}$ \\
\hline $\begin{array}{l}\text { Awareness of various social } \\
\text { situations (12) }\end{array}$ & $\begin{array}{l}\text { "The understanding of right or wrong events in society and the reasoning on such events including when students } \\
\text { sympathize with their friends, the (bullying) behaviors will stop" }\end{array}$ \\
\hline \multicolumn{2}{|l|}{ Social information processing } \\
\hline $\begin{array}{l}\text { Understanding the behaviors of } \\
\text { others (7) }\end{array}$ & $\begin{array}{l}\text { "We must give in because she is a woman; Don't bully each other; Listen to me, we are men, we have advantage over } \\
\text { women; If it becomes a big problem, the troubles will find your parents" }\end{array}$ \\
\hline Understanding social situations (11) & $\begin{array}{l}\text { "Making students with bullying behaviors aware of social situations will enhance their thinking and decision-making } \\
\text { skills for that situation; This will help teenagers to know how to choose the right and appropriate expressions for } \\
\text { interacting with others in the society" }\end{array}$ \\
\hline \multicolumn{2}{|l|}{ Social skills } \\
\hline $\begin{array}{l}\text { Appropriate expression of emotions } \\
\text { (9) }\end{array}$ & $\begin{array}{l}\text { "Try to teach him that some incidents are too insignificant to matter, then he should let it go and control himself; These } \\
\text { days, students sometimes just can't control themselves in response to a small incident, which causes it to become a } \\
\text { big problem; Maybe if it is a small problem, they should let it be" }\end{array}$ \\
\hline Appropriate behaviors (14) & $\begin{array}{l}\text { "The reason for students to bully their friends is mostly from themselves; While being with their families, they may } \\
\text { often encounter domestic violence; Some students are just spoiled by their families, and not disciplined on appropriate } \\
\text { behaviors; It seems like they lack social skills" }\end{array}$ \\
\hline
\end{tabular}

${ }^{1} T$ The number in parentheses is the number of the key informants who addressed each component of social intelligence. 
conclusion, all of which focused on enhancing emotions, feelings, thinking processes, and behaviors. The program was designed to run for a total of 8 weeks, with 8 counseling sessions per program. The details of the entire program are shown in Table 2.

\section{Phase 2}

\section{The quantitative study results}

The demographic data of the participants are shown in Table 3. No loss to follow-up occurred, and no statistically significant differences in basic background characteristics were found between the experimental and control groups, including gender, age, education level, or cumulative grades. The baseline SIS score and BBS score showed no significant between-group differences. Upon completion of the social intelligence coun- seling program, changes in social intelligence in the experimental group were examined by comparing differences in the SIS scores between the 2 groups. The results showed that the experimental group had an increased mean SIS score (7.87 \pm 6.53), while the control group had a decreased mean SIS score $(-5.82 \pm 8.56)$, with a significant difference between the 2 groups. Moreover, when stratified by each social intelligence component, significant differences were observed between the 2 groups. The details are shown in Table 4.

For bullying behavioral changes, the data were followed up 1 month after completion of the individual counseling program in both groups. The data were analyzed to compare the BBS within each group before and after participating in the social intelligence counseling program, as shown in Table 4. The findings indicated that the experimental group had a mean BBS

Table 2. Details of the social intelligence counseling program in this study

\begin{tabular}{|c|c|c|}
\hline Counseling sessions (theme) ${ }^{1}$ & Activities & Expected outcome \\
\hline \multicolumn{3}{|l|}{ Week 1: You and I } \\
\hline $\begin{array}{l}\text { Objective(s): To create an atmosphere of } \\
\text { trust, warmth and friendliness, which } \\
\text { encourages mutual acceptance between } \\
\text { the counselor and the counselee } \\
\text { Theory and counseling technique(s): } \\
\text { Theory: person-centered counseling } \\
\text { theory } \\
\text { Techniques: listening, questioning, } \\
\text { unconditional positive regard, attention, } \\
\text { reflection on feelings, clarifying }\end{array}$ & $\begin{array}{l}\text { Create relationships between the counselor and the counselee } \\
\text { Explain the objectives and the benefits of attending the program and give } \\
\text { the counselee an opportunity to share his or her expectations } \\
\text { Ask questions to assess and allow the counselee to understand social } \\
\text { intelligence } \\
\text { Jointly summarize the benefits of social intelligence }\end{array}$ & $\begin{array}{l}\text { Trust established with the } \\
\text { counselee, resulting in effective } \\
\text { execution of the social } \\
\text { intelligence counseling } \\
\text { program }\end{array}$ \\
\hline \multicolumn{3}{|l|}{ Week 2: Understanding emotional awareness } \\
\hline $\begin{array}{l}\text { Objective(s): For the counselee to } \\
\text { understand and be aware of his or her } \\
\text { feelings and emotions and those of } \\
\text { others } \\
\text { Theory and counseling technique(s): } \\
\text { Theory: Gestalt counseling theory } \\
\text { Technique: think-feel technique }\end{array}$ & $\begin{array}{l}\text { Review the benefits of social intelligence } \\
\text { Allow the counselee to close his or her eyes for } 2 \text { minutes to recall past } \\
\text { events } \\
\text { Have the counselee draw a picture of "my goodness" and a picture of } \\
\text { "a friend's goodness" and explain their feelings } \\
\text { Ask questions about how to understand people to develop an ability to } \\
\text { understand others' emotions in various situations } \\
\text { Explain and connect the thoughts, feelings and perceptions of the } \\
\text { counselee to understand the feelings of a person being bullied } \\
\text { Jointly summarize the counselee's participation in this session }\end{array}$ & $\begin{array}{l}\text { The counselee gains awareness } \\
\text { and an understanding of their } \\
\text { feelings and those of others, } \\
\text { especially the thoughts and } \\
\text { feelings of a person being } \\
\text { bullied }\end{array}$ \\
\hline \multicolumn{3}{|l|}{ Week 3: Understanding social awareness } \\
\hline $\begin{array}{l}\text { Objective(s): For the counselee to correctly } \\
\text { understand social situations } \\
\text { Theory and counseling technique(s): } \\
\text { Theory: Gestalt counseling theory } \\
\text { Techniques: stay with a feeling, fantasy } \\
\text { approaches }\end{array}$ & $\begin{array}{l}\text { Greet and talk about various situations in society } \\
\text { Use the "stay with a feeling" technique to allow the counselee to think } \\
\text { about a social situation and ask about the situation and the feelings of } \\
\text { the counselee } \\
\text { Have the counselee choose a question card about a bullying situation in } \\
\text { society, use this question to ask how the counselee feels about the } \\
\text { situation on the card, about the cause of the situation, and whether the } \\
\text { counselee has experienced a similar situation } \\
\text { Jointly share opinions and views on the situation } \\
\text { Conduct awareness exercises and jointly summarize the counselee's } \\
\text { participation in this session }\end{array}$ & $\begin{array}{l}\text { The counselee gains an } \\
\text { awareness of the social } \\
\text { situations around himself or } \\
\text { herself and an understanding } \\
\text { of the behavioral expressions } \\
\text { of others and learns to respond } \\
\text { appropriately }\end{array}$ \\
\hline
\end{tabular}


Table 2. Continued from the previous page

\section{Counseling sessions (theme)}

Week 4: Enhancing decisions regarding the treatment of others

Objective(s): To enhance the counselee's understanding of the behaviors of others in social situations

Theory and counseling technique(s): Theory: behavioral counseling theory Technique: problem-solving
Discuss the daily routines of the counselee

Have the counselee visualize various bullying situations and ask questions:

"How do the people in these situations feel?"

"What do the people in these situations want?"

Support and allow the counselee to freely express his or her views about situations and people in society

Have the counselee try to understand the simulation and answer the question of "how to solve this problem"

Jointly gather concepts and summarize participation in this session

\section{Week 5: Enhancing social information processing}

Objective(s): To enhance the counselee's understanding of social situations when deciding to express appropriate behaviors

Theory and counseling technique(s): Theory: Gestalt counseling theory Techniques: fantasy approaches

\section{Week 6: Developing emotions}

Objective(s): To develop appropriate emotional expressions in front of others

Theory and counseling technique(s): Theory: behavioral counseling theory Techniques: skills training, reinforcement, assign homework

\section{Week 7: Developing behaviors}

Objective(s): To develop the ability to express appropriate behaviors in front of others

Theory and counseling technique(s): Theory: behavioral counseling theory Techniques: modeling, assign homework
Greet and ask about the experiences of the counselee from previous sessions

Allow the counselee to use "fantasy approaches" to imagine life events that cause inappropriate behaviors and the impact of these events

Jointly share opinions about inappropriate behaviors and proper social etiquette

Use open-ended questions about how the counselee should behave upon encountering a teacher, a monk, his or her father or mother, relatives, or close friends

Provide knowledge about etiquette in daily life and perform some exercises for "basic social etiquette"

Jointly summarize participation in this session

Discuss and exchange various stories to create a friendly atmosphere

Provide knowledge of "emotions and feelings in everyday life"

Have the counselee review his or her thoughts and feelings upon encountering a simulation; for example, when receiving a compliment from a teacher for having the highest exam score, when being teased or attacked by a friend

Do "skills training" for appropriate expressions of feelings

Give a "homework assignment" to practice "complimenting others"

\section{Expected outcome}

The counselee understands the behaviors of others in social situations, which informs their decisions regarding how to treat others
The counselee understands proper social etiquette and orders of society to understand social information and use it in decisions to show appropriate behaviors in each situation
Greet and have the counselee present homework on "complimenting others"

Have the counselee think of inappropriate behaviors that he or she has experienced or displayed and write down these inappropriate behaviors and their attitudes toward such behaviors

Have the counselee look at a picture set showing bullying behaviors and share a reflection of his or her feelings and beliefs about the behaviors and discuss each behavior with the counselee

Use the "modeling" technique for the counselee to practice the appropriate behavior shown in pictures of "good behavior for teenagers"

Give a "homework assignment" to make a record of "my good behaviors"

\section{Week 8: Success in social intelligence}

Objective(s): To review learning and reflective learning outcomes after participating in the psychological counseling program to enhance social intelligence

Theory and counseling technique(s):

Theories: person-centered counseling theory

Techniques: open-ended questions, summarizing, clarifying, encouragement
Greet the counselee and ask what he or she has learned from the previous homework assignment

Explain the purpose of this counseling session to lead to the end of the consultation

Ask questions to assess the learning outcomes of the counselee; for example, what the counselee learned and what benefits the counselee gained

Have the counselee complete a "reflective learning" worksheet and provide an opportunity to ask additional questions

Encourage the counselee to gain confidence in applying social intelligence in daily life
The counselee can appropriately behave in front of others, including communication, facial expressions, postures, and maintaining good relationships

${ }^{1} A$ total of 8 weeks: 8 weekly 1-hour counseling sessions. 
score that was significantly lower than that before participating in the counseling program $(p<0.001)$. However, no significant differences were found in the mean BBS scores of the control group between the 2 time periods.

Table 3. Demographic data of the participants between the experimental and control groups $(n=32)$

\begin{tabular}{|c|c|c|c|c|}
\hline Variables & $\begin{array}{l}\text { Experimental } \\
\quad(n=16)\end{array}$ & $\begin{array}{l}\text { Control } \\
(n=16)\end{array}$ & Total & $p$-value \\
\hline Sex & & & & 1.000 \\
\hline Male & 16 & 15 & 31 (96.9) & \\
\hline Female & - & 1 & $1(3.1)$ & \\
\hline Age (y) & & & & 0.918 \\
\hline 12 & 1 & 1 & $2(6.3)$ & \\
\hline 13 & 10 & 8 & 18 (56.2) & \\
\hline 14 & 4 & 6 & 10 (31.2) & \\
\hline 16 & 1 & 1 & $2(6.3)$ & \\
\hline Education level & & & & 0.484 \\
\hline Grade 8 & 16 & 14 & 30 (93.7) & \\
\hline Grade 9 & - & 2 & $2(6.3)$ & \\
\hline Cumulative grade & & & & 0.241 \\
\hline$\leq 2.00$ & 4 & 6 & 10 (31.2) & \\
\hline $2.01-3.00$ & 9 & 4 & $13(40.6)$ & \\
\hline$>3.00$ & 3 & 6 & $9(28.2)$ & \\
\hline
\end{tabular}

Values are presented as number or number (\%).

'Fisher's exact test/Exact test.
With regard to the main objective of this study, bullying behaviors after counseling between the experimental and control groups were assessed using one-way ANOVA. The post-counseling BBS score in the experimental group was lower than that in the control group. The BBS change after the counseling program had the same level of significance as the result for changes in social intelligence.

\section{The qualitative study results}

The overall qualitative results were analyzed by considering the information from the in-depth interviews in the experimental group together with the SIS from the Tromso social intelligence questionnaire after the completion of counseling. These results were used to more clearly explain the effectiveness of the individual social intelligence counseling program. The results indicated that one important factor reinforcing the social intelligence of students who demonstrated bullying behaviors was promoting social awareness to help them become aware of themselves and others, be able to perceive and understand the emotions and feelings of others, acknowledge the perspectives of other people in society, and have sympathy and empathy for others, all of which could lead to reductions in their bullying behaviors, as in the following sample statements by key informants who previously displayed physical and verbal bullying behaviors:

Table 4. Comparison of scores of SIS and its components, and BBS scores between the experimental and control group before and after counseling $(n=32)$

\begin{tabular}{|c|c|c|c|c|}
\hline Variables & Experimental $(n=16)$ & Control $(n=16)$ & Mean difference $(95 \% \mathrm{Cl})$ & $p$-value \\
\hline \multicolumn{5}{|l|}{ Total SIS scores } \\
\hline Baseline & $62.38 \pm 5.83$ & $60.63 \pm 6.05$ & $1.75(-2.54,6.04)$ & 0.411 \\
\hline End of counseling & $70.25 \pm 4.30$ & $54.81 \pm 9.73$ & $15.44(9.90,20.97)$ & $<0.001$ \\
\hline \multicolumn{5}{|c|}{ Social intelligence components } \\
\hline \multicolumn{5}{|c|}{ Social awareness scores } \\
\hline Baseline & $17.56 \pm 3.33$ & $18.44 \pm 3.14$ & $-0.88(-3.21,1.46)$ & 0.450 \\
\hline End of counseling & $21.00 \pm 3.93$ & $17.38 \pm 3.98$ & $3.63(0.77,6.48)$ & 0.015 \\
\hline \multicolumn{5}{|c|}{ Social information processing scores } \\
\hline Baseline & $23.50 \pm 3.69$ & $22.13 \pm 3.48$ & $1.38(-1.21,3.96)$ & 0.287 \\
\hline End of counseling & $26.56 \pm 3.58$ & $19.56 \pm 4.60$ & $7.00(4.02,9.98)$ & $<0.001$ \\
\hline \multicolumn{5}{|l|}{ Social skills scores } \\
\hline Baseline & $21.31 \pm 3.05$ & $20.06 \pm 2.77$ & $1.25(-0.85,3.35)$ & 0.234 \\
\hline End of counseling & $22.69 \pm 2.18$ & $17.88 \pm 3.24$ & $4.81(2.82,6.81)$ & $<0.001$ \\
\hline \multicolumn{5}{|l|}{ BBS scores } \\
\hline Baseline & $34.81 \pm 12.61$ & $33.38 \pm 9.11$ & $1.44(-6.51,9.38)$ & 0.714 \\
\hline 1-mo post-counseling & $22.44 \pm 7.87$ & $33.25 \pm 9.36$ & $-10.81(-17.05,-4.57)$ & 0.001 \\
\hline
\end{tabular}

Values are presented as mean \pm standard deviation.

SIS, Social Intelligence Scale; BBS, Bullying-Behavior Scale; Cl, confidence interval. 
"From a person who likes to tease friends and gossip about others, I changed recently. I just put myself in their shoes."

(The first counselee, a 13-year-old male in grade 8)

"If we know and understand the feelings of others, we can live together in our society. If we do not tease our friends, they will come to make friends with us, and then we can also live happily together in our friends' company."

(The sixth counselee, a 14-year-old male in grade 8)

Another way to change bullying behavior is to encourage students to think analytically by analyzing advantages and disadvantages, as well as other effects that will emerge, before demonstrating these behaviors, as shown in the following sample statements from key informants:

"Doing good things is something our society needs. Our society needs goodness to improve ourselves to be better. Teasing friends makes them hurt. So if we can improve ourselves, we will not tease them anymore."

(The third counselee, a 12-year-old male in grade 8)

"Good behavior helps other people when they are in distress or trouble. We should listen to them closely and reasonably. We should not use our emotions when making decisions and [we should] not bully other people. These things make us very proud of ourselves."

(The fourth counselee, a 13-year-old male in grade 8)

The improvement of the social skills of students who demonstrate bullying behaviors can give them the ability to express their emotions and behaviors more appropriately, which resolves the problem of bullying among students, as demonstrated in the following sample statements from key informants:

\section{"We can socialize with other people without bullying them."}

(The second counselee, a 13-year-old male in grade 8)

"If we follow the rules, do not break the rules, and do not hurt others, then we can live together and it makes us feel good."

(The fifth counselee, a 13-year-old male in grade 8)

"At first, I was not that good of a person. After I learned and gained some more knowledge from other people, I can live in society. I no longer tease anybody and understand them well now."

(The sixth counselee, a 14-year-old male in grade 8)
Overall, the qualitative findings confirmed the changes of the students observed in the experimental results. The students achieved all the components of social intelligence that were incorporated into the design of the social intelligence counseling program in this study.

\section{DISCUSSION}

Bullying has been recognized as an important community mental health issue. Effective prevention measures and interventions for this problem need to be explored. The results of this study provide evidence to support effective interventions. The experimental results of the social intelligence counseling intervention indicated that it was effective in enhancing social intelligence and reducing bullying behaviors among students who demonstrated those behaviors. This observation is supported in terms of the study hypothesis by the increase in the social intelligence scores of the experimental group after participation. The quantitative and qualitative results indicated that the received intervention group achieved all of the components of social intelligence: social awareness, social information processing, and social skills. During the follow-up after counseling, their BBS scores also decreased significantly compared to those in the control group, indicating that the enhancement of social intelligence can reduce bullying behaviors among those students who demonstrated them. This finding is consistent with the study of Sameer [10], which stated that students with high social intelligence would demonstrate less aggressive behavior, while students with low social intelligence would have more aggressive behavior.

The process of developing a counseling program based on qualitative research in this study comprised social awareness, social information processing, and social skills, as detailed in the Results section. These results are also consistent with the social intelligence enhancement approach suggested by Goleman [12], Albrecht [13], and Zautra et al. [22] The details of each component related to decreasing bullying behavior were as follows: first, the enhancement of social awareness involves improving the awareness of the feelings of students and the feelings of people being bullied, which allows students to acknowledge the views and feelings of others, leading to sympathy for those who are bullied, which is consistent with Patrick et al. [23]. Consequently, adapting easily to others results in decreased bullying behaviors. Second, the enhancement of social information processing allows students to analyze social events and gain 
the ability to assess and make decisions on how to behave appropriately in various situations. Social information is used to develop the thinking and analytical processes of events or individuals in society. Students are encouraged to analyze the advantages, disadvantages, and effects or consequences before expressing bullying behaviors. Last, the enhancement of social skills enhances the ability of students to live with others and express and build relationships with others without expressing bullying behaviors. The students also gain the ability to express emotions and behave appropriately, which can lead to solving bullying problems among students $[24,25]$.

This counseling intervention was a collaborative effort between counselors and clients, who were students who had engaged in bullying behavior. They helped clients identify goals and potential solutions to problems that cause emotional turmoil, improve communication and coping skills, strengthen self-esteem, and promote behavioral changes and optimal mental health. The program involved a process of unlocking one's potential by developing feelings, behaviors, and thoughts. Ultimately, the counselee will be able to develop, change, accept problems, create appropriate alternatives, perform their duties, and find ways to deal with problems $[9,26]$. Moreover, counseling is a communication approach with principles that help to solve problems and promote self-improvement [27]. Counseling is a relatively straightforward way to control the problem of bullying before students become violent at school. This developed counseling program covered both external and internal behavior development, including the feeling, thinking, and behavior of students reducing bullying behaviors. It is superior to other approaches, such as that of Permata et al. [28], who created a program that emphasized only external behavior development. However, the retention of social intelligence may need exploration in the future.

From the utilization perspective, the individual social intelligence counseling program developed in this study is a new, alternative and preventive program to solve bullying behavior problems. The advantage of this indicated preventive program is that it provides a more specific intervention approach. It does not need a professional health team, such as mental health staffs or social workers, to conduct a multitiered intervention in life or activity domains [26]. More targeted prevention could save more costs than the existing universal program and practice. An individual-focused program could decrease students' stigma and increase perceptions of the school safety climate [6]. This integrated counseling program was developed through the eclecticism technique, which integrates various effective techniques from different existing theories, including personcentered counseling theory, Gestalt counseling theory, and behavior counseling theory. Bullying behaviors might result in different problems. Therefore, an advantage of this integrated counseling is that it is flexible and not limited to specific theories or behavioral therapies compared to other types of integrative counseling, such as assimilative and theoretical integration [26]. Additionally, it is suitable and effectively applied in real-life settings to guide teachers in school counseling competency customization to cater to students who demonstrate bullying behaviors in different situations [25-27].

Nonetheless, this study has limitations. First, the information obtained from this sample of students had sufficient statistical power to prove a significant decrease in bullying behaviors after counseling. However, the small sample size and the population of lower secondary school students resulted in an inability to perform subgroup analysis or sophisticated statistical analyses to obtain more information about the consistency of the program's effectiveness in particular subgroups. Further studies need to explore the support of this counseling program as an alternative intervention and apply it to students at other education levels. Second, bullying behaviors were evaluated by a self-report that may be difficult for people in this age range to answer. Future studies should expand to a larger scale using more objective assessments of bullying behaviors, such as analyzing incident records in the student support system, interviewing homeroom teachers and people in the student environment, and evaluating other outcomes (e.g., the results of student learning) after the enhancement of their social intelligence.

In conclusion, the indicated preventive intervention for reduced bullying behavior with an individual social intelligence counseling program was developed based on the technique of eclecticism. Students were encouraged to express emotions and behavior appropriately through enhancements of their social awareness, social information processing, and social skills. The effectiveness of this integrative counseling program, as demonstrated by mixed-method qualitative and quantitative research with control internal validity, demonstrated that this intervention was effective in enhancing social intelligence among lower secondary school students who demonstrated bullying behaviors, resulting in a significant reduction in bullying and preventing school violence. Remarkably, social intelligence was found to promote healthy emotions and behaviors. 
However, further studies in various population subgroups should also be performed.

\section{CONFLICT OF INTEREST}

The authors have no conflicts of interest associated with the material presented in this paper.

\section{FUNDING}

This research was supported by the National Research Council of Thailand.

\section{ACKNOWLEDGEMENTS}

The authors would like to thank everyone involved with this research, including the key informants, students, teachers, school directors and experts. Additionally, the authors thank Professor Dr. Low Wah Yun.

\section{AUTHOR CONTRIBUTIONS}

Conceptualization: SJ, CE. Data curation: SJ. Formal analysis: SJ, CE. Funding acquisition: SJ, CE. Methodology: OS, CE. Project administration: SJ, CE. Validation: OS. Writing - original draft: SJ. Writing - review \& editing: SJ, OS, CE.

\section{ORCID}

Samith Jueajinda $\quad$ https://orcid.org/0000-0002-9002-3008

Orapin Stiramon https://orcid.org/0000-0002-0498-8066 Chatchai Ekpanyaskul

https://orcid.org/0000-0002-2906-9832

\section{REFERENCES}

1. United Nations Educational, Scientific and Cultural Organization. School violence and bullying global status report; 2017 [cited 2020 Jun 7]. Available from: https://unesdoc.unesco. org/ark:/48223/pf0000246970.

2. World Health Organization. Preventing youth violence: an overview of the evidence; 2015 [cited 2020 Jun 7]. Available from: https://apps.who.int/iris/handle/10665/181008.

3. Department of Mental Health, Ministry of Public Health. Bullying among children in Thailand is a world ranking second only to Japan; 2019 [cited 2020 Jun 7]. Available from: https:// www.dmh.go.th/news-dmh/view.asp?id=27511 (Thai).

4. Walters GD, Espelage DL. From victim to victimizer: hostility, anger, and depression as mediators of the bullying victimization-bullying perpetration association. J Sch Psychol 2018;68: 73-83.

5. Sivaraman B, Nye E, Bowes L. School-based anti-bullying interventions for adolescents in low-and middle-income countries: a systematic review. Aggress Violent Behav 2019;45:154162.

6. Earnshaw VA, Reisner SL, Menino D, Poteat VP, Bogart LM, Barnes TN, et al. Stigma-based bullying interventions: a systematic review. Dev Rev 2018;48:178-200.

7. Cho S, Lee JM. Explaining physical, verbal, and social bullying among bullies, victims of bullying, and bully-victims: assessing the integrated approach between social control and lifestylesroutine activities theories. Child Youth Serv Rev 2018;91:372382.

8. National Academies of Sciences, Engineering, and Medicine. Preventing bullying through science, policy, and practice. Washington, DC: National Academies Press; 2016, p. 179-252.

9. Corey $\mathrm{G}$. Theory and practice of counseling and psychotherapy. 9th ed. Belmont: Brooks Cole Cengage Learning; 2013, p. 7-282.

10. Sameer BM. Social intelligence and aggression among senior secondary school students: a comparative sketch; 2007 [cited 2019 Nov 8]. Available from: https://eric.ed.gov/?id=ED500484.

11. Shekarey A, Ladani HJ, Rostami MS, Jamshidi M. On the relationship between the social intelligence and aggression: a case study of high school boy students. Int J Educ 2013;5(1): 94-102.

12. Goleman D. Social intelligence: the new science of human relationships. New York: Bantam Books; 2006, p. 8.

13. Albrecht K. Social intelligence: the new science of success. San Francisco: Jossey-Bass; 2006, p. 12-13.

14. Creswell JW. A concise introduction to mixed methods research. Thousand Oaks: SAGE; 2015, p. 1-7.

15. Guest $\mathrm{G}$, Bunce A, Johnson L. How many interviews are enough? An experiment with data saturation and variability. Field Methods 2006;18(1):59-82.

16. Faul F, Erdfelder E, Lang AG, Buchner A. G*Power 3: a flexible statistical power analysis program for the social, behavioral, and biomedical sciences. Behav Res Methods 2007;39(2):175191.

17. Silvera DH, Martinussen M, Dahl TI. The Tromsø Social Intelli- 
gence Scale, a self-report measure of social intelligence. Scand J Psychol 2001;42(4):313-319.

18. Olweus D. The revised Olweus Bully/Victim Questionnaire. Bergen: University of Bergen; 1996, p. 17-36.

19. Tapanya S. Final report: a study to develop the model for sustainable prevention violence against children. Chiang Mai: Chiang Mai University; 2007, p. 24-36 (Thai).

20. Solberg ME, Olweus D. Prevalence estimation of school bullying with the Olweus Bully/Victim Questionnaire. Aggr Behav 2003;29(3):239-268.

21. Larson-Hall J. A guide to doing statistics in second language research using SPSS. New York: Routledge; 2009, p. 139-144.

22. Zautra EK, Zautra AJ, Gallardo CE, Velasco L. Can we learn to treat one another better? A test of a social intelligence curriculum. PLoS One 2015;10(6):e0128638.

23. Patrick RB, Rote WM, Gibbs JC, Basinger KS. Defend, stand by, or join in?: the relative influence of moral identity, moral judgment, and social self-efficacy on adolescents' bystander be- haviors in bullying situations. J Youth Adolesc 2019;48(10): 2051-2064.

24. Pöyhönen V, Juvonen J, Salmivalli C. Standing up for the victim, siding with the bully or standing by? Bystander responses in bullying situations. Soc Dev 2012;21(4):722-741.

25. Veenstra R, Lindenberg S, Huitsing G, Sainio M, Salmivalli C. The role of teachers in bullying: the relation between antibullying attitudes, efficacy, and efforts to reduce bullying. J Educ Psychol 2014;106(4):1135-1143.

26. Chan F. Counseling theories and techniques for rehabilitation and mental health professionals. New York: Springer; 2015, p. 74-76.

27. Sharf RS. Theories of psychotherapy \& counseling: concepts and cases. 5th ed. Belmont: Brooks Cole; 2012, p. 4.

28. Permata SA, Thahir A, Utami FP. Reality counseling with value judgement techniques to reduce bullying behavior of vocational students. Psychol Res Educ Soc Sci 2020;1(2):83-89. 